\title{
Mental well-being of the general population: direct and indirect effects of socioeconomic, relational and health factors
}

\author{
Natalia Soldevila-Domenech ${ }^{1,2,3}$ (]) $\cdot$ Carlos G. Forero ${ }^{4}$ - Itxaso Alayo ${ }^{1,5} \cdot$ Jordina Capella $^{6,10}$ (D) Joan Colom ${ }^{6}$ (D) \\ Davide Malmusi ${ }^{5,7}$ (D) Anna Mompart ${ }^{8} \cdot$ Philippe Mortier $^{1,5}$ (D) $\cdot$ Beatriz Puértolas $^{1,5} \cdot$ Néstor Sánchez $^{4}$ (D) \\ Anna Schiaffino ${ }^{8,9}$ (D) Gemma Vilagut $^{1,5}$ (D) Jordi Alonso ${ }^{1,3,5}$ (D)
}

Accepted: 3 March 2021 / Published online: 13 April 2021

(c) The Author(s) 2021

\begin{abstract}
Purpose The aim of this study was to analyse the association between individual mental well-being and social, economic, lifestyle and health factors.

Methods Cross-sectional study on a representative sample of 13,632 participants ( $>15 y / 0)$ from the Catalan Health Interview Survey 2013-2016 editions. Mental well-being was assessed with the Warwick-Edinburg Mental Well-being Scale (WEMWBS). Linear regressions were fitted to associate well-being and sociodemographic, relational, lifestyle and health variables according to minimally sufficient adjustment sets identified using directed acyclic graphs. Predictors entered the model in blocks of variable types and analysed individually. Direct and total effects were estimated.

Results Health factors significantly contributed to mental well-being variance. Presence of a mental disorder and selfreported health had the largest effect size $\left(\mathrm{eta}^{2}=13.4 \%\right.$ and $\left.16.3 \%\right)$. The higher individual impact from a variable came from social support $\left(\beta=-12.8, \mathrm{SE}=0.48\right.$, eta $\left.{ }^{2}=6.3 \%\right)$. A noticeable effect gradient $\left(\mathrm{eta}^{2}=4.2 \%\right)$ from low to high mental wellbeing emerged according to economic difficulties (from $\beta=1.59, \mathrm{SE}=0.33$ for moderate difficulties to $\beta=6.02 \mathrm{SE}=0.55$ for no difficulties). Younger age $\left(\beta=5.21, \mathrm{SE}=0.26\right.$, eta $\left.{ }^{2}=3.4 \%\right)$ and being men $\left(\beta=1.32, \mathrm{SE}=0.15\right.$, eta $\left.{ }^{2}=0.6 \%\right)$ were associated with better mental well-being. Direct gender effects were negligible.

Conclusions This study highlights health and social support as the most associated factors with individual mental well-being over socioeconomic factors. Interventions and policies aimed to these factors for health promotion would improve population mental well-being.
\end{abstract}

Keywords Well-being $\cdot$ WEMWBS $\cdot$ Mental health $\cdot$ Health determinants $\cdot$ Health survey $\cdot$ Directed acyclic graphs

\section{Plain English summary}

Mental well-being is typically understood as 'feeling good' and 'functioning well' and it is considered an indicator of societal progress. However, there is a lack of knowledge about its risk and protective factors. The study of drivers of mental well-being is important to understand how mental

Natalia Soldevila-Domenech and Carlos G. Forero these authors are contributed equally.

\section{Gemma Vilagut \\ gvilagut@imim.es \\ Jordi Alonso \\ jalonso@imim.es}

Extended author information available on the last page of the article health operates in the population beyond mental illness. In this study, we explored the impact of demographic, socioeconomic, relational, lifestyle and health factors on the mental well-being, in a representative general population sample of 13,632 individuals. This study indicates that mental well-being is sensitive to demographic and socioeconomic factors such as gender, age, education, employment and economic difficulties, as well as, to relational and health factors. Adverse health factors and self-reported health are most strongly associated with mental well-being over socioeconomic factors, which would have an indirect impact on mental well-being. Finally, the lack of social support appears as a critical risk factor of decreased mental well-being. Findings from this study suggest that interventions and policies aimed for health promotion would improve population mental well-being. 


\section{Introduction}

The evaluation of well-being at the individual level receives increasing attention for its potential impact on health, economy and societal progress $[1,2]$. The World Health Organisation (WHO) emphasizes that 'there is no health without mental health', which includes aspects of psychological, emotional and social well-being [3]. Mental well-being, defined as 'feeling good' and 'functioning well' [4], may generate resilience to mental and physical illnesses, boost educational achievement, enhance performance in the workplace and increase longevity in the general population $[5,6]$. Consequently, promoting mental well-being may also be a useful approach to health promotion and disease prevention [7]. To achieve this, we need more evidence on its risk and protective factors $[8,9]$.

In the WHO model of social determinants of health and well-being [10], the socioeconomic and political context gives rise to structural determinants of health (gender, age, ethnicity, social class), responsible of health inequalities by influencing how people live and work and affecting the exposure to risk and protective factors over the life course. The socioeconomic status (education, employment and money) puts people in economic difficulties at "risk of risk" [11], conditioning proximal determinants of mental well-being, including relational factors (e.g. social support), health factors (e.g. physical and mental disorders, disability) and perceived health [12]. Similarly, the pathway from lifestyle factors to well-being would act as risk or protective factors of mental and physical disorders [13]. Among relational factors, functional social support provides emotional, instrumental and informational resources, which have been identified as affected by unemployment, retirement or economic difficulties [11, 12]. Social support may directly impact mental well-being by promoting the sense of belonging, enhancing self-realization and increasing coping abilities $[14,15]$.

Some authors suggest that mental disorders may have stronger effects on mental well-being than physical disorders due to the higher personal uncertainty and compromised ability to display adaptive conducts associated with such conditions [16]. Also because of adaptation, recent acute health problems may have a higher impact on well-being than long-term chronic conditions [17, 18]. Disability would mediate the impact of physical and mental conditions on perceived health [19], and could also impact mental wellbeing directly due to its pervasive effects on major areas of everyday life. Self-perceived health status reflects both the actual physical condition and its emotional impact on general living conditions [20]. Actually, there is evidence that the relative effect of self-reported health on well-being is larger than that of income and social relationships [15].
Identifying the causal direction among these factors is not straightforward. Also, to date, determinants of mental well-being as an outcome have been researched with various instruments more focussed on mental disorders rather than on positive aspects of mental health. In recent years, the Warwick Edinburgh Mental Well-being Scale (WEMWBS) has emerged as an increasingly popular individual-level measure of positive mental well-being [21]. Studies using WEMWBS have shown that mental well-being does not mirror the traditional gradients reported for mental illness [22] and that its predictors differ from those of psychopathology [23], making it a potentially informative instrument for analysing population mental well-being.

A better comprehension of the drivers of positive mental health would increase our understanding of how mental health operates in the population beyond mental illness. Such understanding would boost our ability to monitor public health policies and interventions for promoting population health. In this study, we aim to identify potential determinants of population mental well-being, as measured with the WEMWBS, using data from a large representative population sample of the Catalan population (Spain). Specifically, and based on the general WHO model of health determinants, we intend to estimate the associations between mental well-being and demographic, socioeconomic, relational, lifestyle and health-related blocks of variables, as well as analysing the direct and indirect effect of each specific variable on mental well-being. We hypothesized (1) the existence of social inequalities in the distribution of mental well-being; (2) a higher contribution of relational and health factors to the mental well-being over lifestyle, socioeconomic and demographic factors; and (3) a substantial positive contribution of health factors and self-perceived health on the indirect effect of each variable on mental well-being.

\section{Methods}

\section{Design, information sources and study population}

Repeated cross-sectional design using data from 7 biannual waves of the Catalan Health Interview Survey (ESCA) during 2013-2016 $(N=13,632)$. Each wave ensues an independent representative sample of the general population (over 15 years old) of Catalonia, a north-eastern region of Spain (7.5 million inhabitants). The sampling frame is the noninstitutionalized adult population in the Population Registry of Catalonia from the Catalan Institute of Statistics (IDESCAT). Individuals are selected through stratified threestage random sampling with different probabilities within strata. The ESCA has the rank of official statistics by the Government of the Catalonia, so participants must answer the survey in a complete and truthful way (Law 23/1998, 
December 30, of statistics of Catalonia). Data are obtained through face-to-face interviews by trained interviewers at the respondent's home using computer-assisted personal interviewing (CAPI). Interview time takes about $45 \mathrm{~min}$ [24].

Study's population features were as follows: $50.9 \%$ women; mean age 47.4 years; $21.3 \%$ had up to primary studies; $14.4 \%$ were born in non-high income countries; $10.7 \%$ were unemployed; $15.1 \%$ were retired, and $20.6 \%$ had difficulties in making monthly ends meet. Low social support was present in $2.5 \%$ women and $1.7 \%$ men. Regarding lifestyle factors, $14.7 \%$ were obese, and $25.5 \%$ were current smokers. As for health factors, $17.0 \%$ reported life-time history of at least one mental disorder $(22.9 \%$ women and $10.9 \%$ men); $63.9 \%$ reported at least one physical disorder $(70.6 \%$ women and $56.9 \%$ men); $8.0 \%$ reported lack of autonomy, and $3.5 \%$ reported "poor" perceived health status. See Table 2 for detailed sample characteristics.

\section{Variables}

\section{Mental well-being}

The primary outcome was mental well-being as measured with Spanish and Catalan versions of the WEMWBS [25, 26]. It is a unidimensional measure of mental well-being in the previous two weeks [21] using 14 Likert-scaled positively-worded items (e.g. "I've been feeling optimistic about the future"), with five categories from "None of the time" to "All of the time". Sumscore ranges 14-70, with higher scores indicating higher levels of mental well-being. The Spanish and English versions of the WEMWBS have shown high internal consistency and reliability (Cronbach's alpha higher than 0.93 and 0.91 , respectively) and adequate discriminative capacity between socioeconomic groups and health-related conditions to perform studies about health, social or economic inequalities [21,25].

\section{Predictive factors of mental well-being}

We explored the WEMWBS relationship with six blocks of factors:

(1) Demographic factors: Sex; Age; and Country of origin, categorized as Spain, high income and other according to the Organisation for Economic Co-operation and Development (OECD) classification [27].

(2) Socioeconomic factors: Educational level (primary or less, secondary, and higher); Employment status (student; employed; unemployed; housework; retired; other); Economic difficulties, obtained from a question about the presence of family economic difficulties to make monthly ends meet; and Social class of the household reference person, based on occupation [28]: class
I (directors, managers and university professionals), class II (intermediate occupations and self-employed workers), class III (manual workers) and not classifiable (never worked and living alone).

(3) Relational factors: Perceived social support was assessed with the DUKE-UNC-11 Functional Social Support Scale, covering confidant support (e.g. chances to talk about work or money problems), and affective support (e.g. displays of affection, love, and empathy) [29]. It has 11 Likert-scaled items, with total score ranging 11-55 points, with higher scores indicating lower social support. In the Spanish validation of the DUKE-UNC-11, a cut-off point at the 15 th percentile was chosen to categorize subjects as 'low' ( $\geq 32$ points) and 'adequate' $(<32$ points) social support [30]. The Spanish version of the DUKE-UNC-11 shows high internal consistency and reliability (Cronbach's alpha of 0.90) [30].

(4) Lifestyle factors: Body mass index (BMI, $\mathrm{kg} / \mathrm{m}^{2}$ ) categorized as: underweight $(\mathrm{BMI}<18.5)$, normal $(18.5 \geq \mathrm{BMI}<25)$, overweight $(25 \geq \mathrm{BMI}<30)$, and obesity (BMI $\geq 30$ ); hours of sleep; and smoking status.

(5) Health factors: Life-time history of mental disorders (anxiety, depression or other mental disorders); lifetime history of long-term ( $\geq 6$ months) physical disorders from a list of 28 [24]; and lack of autonomy, as need of help to perform routine activities due to a health problem.

(6) Self-Perceived health: Using the question: "In general how would you say your health is?" in a 5-point ordinal scale (from Excellent to Poor).

\section{Statistical analysis}

We computed descriptive statistics and standard errors (SE) of WEMWBS scores and study variables, stratified by sex. We tested score differences between categories using oneway analysis of variance (ANOVA), adjusting for multiple comparisons using Benjamini-Hochberg procedure [31] at false discovery rate of 5\%. Effect sizes were computed as either Cohen's d with cut-offs of 0.2 (small), 0.5 (medium), 0.8 (large) and 1.2 (very large) [32, 33] or, in regression models, as eta-squared with cut-offs of $1 \%$ (small), $6 \%$ (moderate) and 14\% (large) [34].

To explore the contribution of each block on mental well-being, we fitted multivariable linear block regression models. Models were devised in a block-nested manner, added from distal to proximal. The first block included demographic factors; the following models added blocks consecutively: socioeconomic factors; relational factors; lifestyle factors; health factors and perceived health. Models increase in explained variance was assessed by block using 
$\mathrm{R}$-squared, and tested using F-test at 0.05 nominal level. The final full model included six blocks and all variables.

We estimated multivariable adjusted linear regression models for each predictor variable. To avoid overadjustment bias [35], we used directed acyclic graph (DAG) methodology to determine the variables for which it is sufficient to control to obtain unbiased estimates of causal effects [36]. DAGs are especially useful for using a priori knowledge (i.e. they use no actual data) on the relation between variables, thus displaying graphically explicit and transparent assumptions based on former available evidence. Relationships are "directed" as variables imply a causal sequence, which are represented by arrows. When there is insufficient evidence to exclude a potential effect between variables, such relationship is also assumed and so is reflected in the DAG. Once a relationship framework is developed, DAGs apply algebraic methods (Pearl's back- and single-door criterion [37-39]) to trim model-biasing pathways, yielding two minimally sufficient adjustment sets (MSAS) for each predictor, one for estimating the total effect and the other for the direct effects (unmediated paths directly connecting a predictor variable and an outcome). The MSAS represent the lowest number of covariates needed for adjusting after excluding irrelevant variables that can actually cause bias when included in the multivariable regression model [40]. Once total and direct effects are estimated, it is possible to decompose total effects in direct and indirect (i.e. remaining effects through paths including mediators and other variables).

We devised a first directed acyclic graph (DAG-1) (Fig. 1), where we assumed that all predictor variables were directly related to mental well-being. Table 1 details on other assumed relationships between covariates. The two suitable MSAS identified from the DAG-1 were entered in two different linear regression models for each predictor, to estimate total and direct effects. Finally, to study whether health factors and self-reported health mediated the effect of all other factors on mental well-being, a second DAG (DAG-2) was devised (Supplementary Figure 2), identical to DAG-1 but excluding health factors and self-reported health from the pathways to well-being. For each predictor, the rate between direct effect differences between DAG-1 and DAG-2 over indirect effects from DAG-1 was computed to study the contribution of health factors and self-perceived health on the indirect effect of each variable on mental well-being. All analyses were adjusted by survey year.

Inverse probability sampling weights and post-stratification weights were applied to achieve representativeness in terms of geographic areas, age, sex, and strata sizes. Weights were normalized to the total sample size so that the samples of each year had equal weights in the analyses. Missing values were $<1.6 \%$ so each specific analysis was performed on individuals with complete information on the variables involved. DAGs and MSAS for total and direct effects were devised using the 'dagitty' package in $\mathrm{R}$ [41]. Data management were done with Stata version 13 [42], and statistical analyses with $\mathrm{R}$ version 3.5.2 [43].

\section{Ethics}

The ESCA has the rank of official statistics carried out by the Government of the Catalonia region, and it must ensure the confidentiality of the data (Law 23/1998, December 30th of statistics of Catalonia).
Fig. 1 Directed acyclic graph (DAG-1). Variable names are abbreviated: origin country of origin; education educational level; work employment status; income family economic difficulties; $B M I$ body mass index; smoke smoking status; sleep hours of sleep; dependency lack of autonomy. Node colours represent the group to which each variable belongs: demographic factors (in blue), socioeconomic factors (in green), relational factors (in purple), lifestyle factors (in grey), health factors (in red), and self-reported health (in orange). (Color figure online)

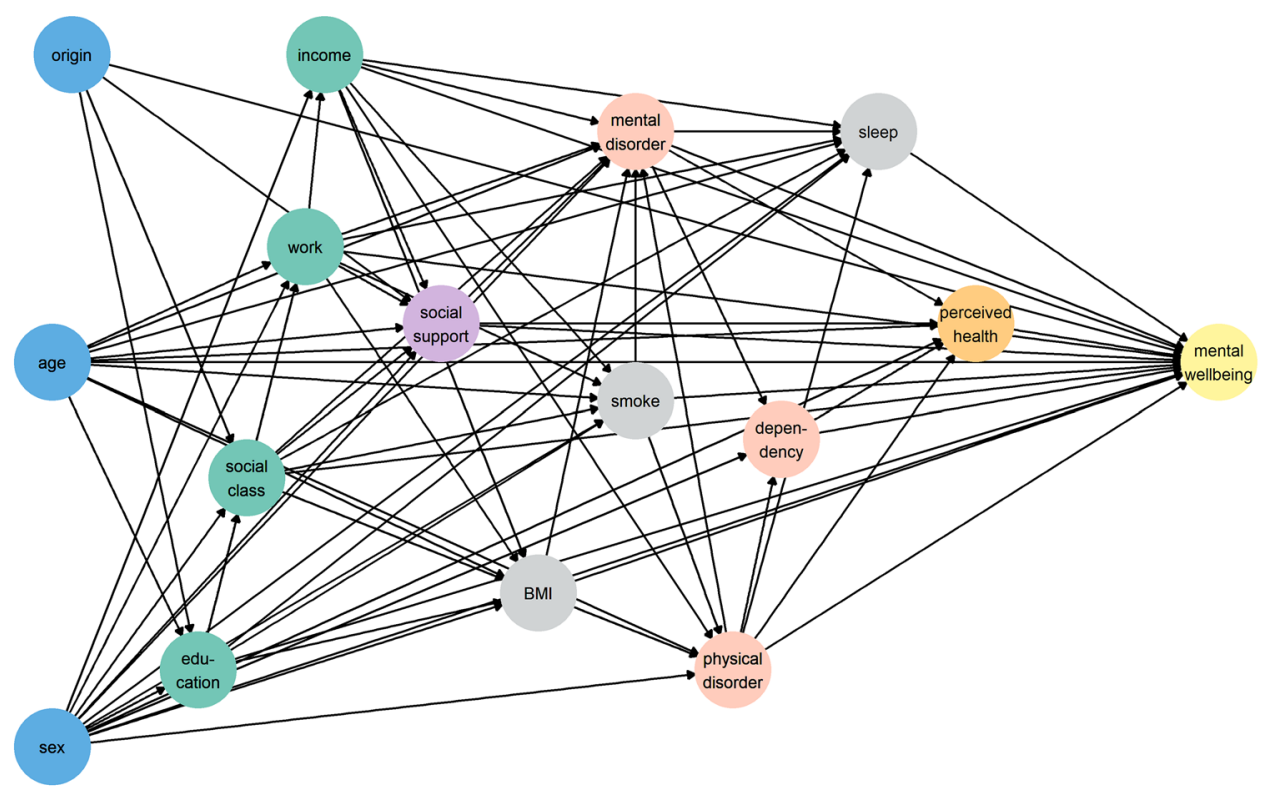


Table 1 Assumed relationships between covariables of mental well-being when developing the DAG

\begin{tabular}{|c|c|c|c|}
\hline \multicolumn{2}{|l|}{ Directed edges } & \multirow{2}{*}{$\begin{array}{l}\text { Potential bidi- } \\
\text { rectionality* }\end{array}$} & \multirow[t]{2}{*}{ References } \\
\hline From & To & & \\
\hline Sex & All variables except age and country of origin & No & {$[61,66,67]$} \\
\hline Age & All variables except sex and country of origin & No & \\
\hline \multirow[t]{3}{*}{ Country of origin } & Education & No & \\
\hline & Social class & No & \\
\hline & Social support & No & \\
\hline \multirow[t]{6}{*}{ Education } & Employment status & Yes $(+)$ & {$[68,69]$} \\
\hline & Social class & Yes $(++)$ & \\
\hline & BMI & No & \\
\hline & Smoking status & No & \\
\hline & Hours of sleep & No & \\
\hline & Mental disorder & Yes $(+)$ & \\
\hline \multirow[t]{7}{*}{ Social class } & Employment status & Yes $(++)$ & {$[70-72]$} \\
\hline & Social support & No & \\
\hline & BMI & No & \\
\hline & Smoking status & No & \\
\hline & Hours of sleep & No & \\
\hline & Physical disorder & No & \\
\hline & Mental disorder & No & \\
\hline \multirow[t]{6}{*}{ Employment status } & Economic difficulties & Yes $(++)$ & \\
\hline & Social support & Yes $(+)$ & \\
\hline & BMI & Yes $(+)$ & \\
\hline & Smoking status & Yes $(+)$ & \\
\hline & Hours of sleep & Yes $(+)$ & \\
\hline & Mental disorder & Yes $(+)$ & \\
\hline \multirow[t]{6}{*}{ Economic difficulties } & Social support & No & \\
\hline & BMI & No & \\
\hline & Smoking status & No & \\
\hline & Hours of sleep & No & \\
\hline & Physical disorder & Yes $(+)$ & \\
\hline & Mental disorder & Yes $(+)$ & \\
\hline \multirow[t]{2}{*}{ Social support } & Mental disorder & Yes $(++)$ & {$[14,55,73]$} \\
\hline & Perceived health & Yes $(+)$ & \\
\hline \multirow[t]{2}{*}{ Body mass index (BMI) } & Physical disorder & Yes $(+++)$ & {$[61,66]$} \\
\hline & Mental disorder & Yes $(+++)$ & \\
\hline \multirow[t]{2}{*}{ Smoking status } & Physical disorder & Yes $(++)$ & \\
\hline & Mental disorder & Yes (+) & \\
\hline \multirow[t]{4}{*}{ Physical disorder } & Hours of sleep & Yes $(+)$ & {$[19,60,74,75]$} \\
\hline & Mental disorder & Yes $(+++)$ & \\
\hline & Lack of autonomy & Yes $(+)$ & \\
\hline & Perceived health & Yes $(++)$ & \\
\hline \multirow[t]{3}{*}{ Mental disorder } & Hours of sleep & Yes $(++)$ & \\
\hline & Lack of autonomy & Yes $(+)$ & \\
\hline & Perceived health & Yes $(++)$ & \\
\hline Lack of autonomy & Perceived health & Yes $(++)$ & \\
\hline
\end{tabular}

*Threatens to the face-validity (plausibility of the posited relationship) are assessed according to evidence, and "Yes" is given in the cases where reverse directionality is plausible. In such cases, the chance of reverse causality is qualitatively evaluated with $(+,++,+++)$, indicating less or more probability of bidirectionality, respectively 


\section{Results}

Table 2 shows descriptive statistics of mental well-being across categories of studied variables (see Supplementary Figure 1 for a visual representation of effect sizes stratified by sex). As expected from the large sample size, all variables showed significant differences in WEMWBS scores. Demographic, socioeconomic and lifestyle factors had small effects on mental well-being. Women presented slightly lower mental well-being than men (58.2 vs 59.5 , Cohen's $d=0.13$ ). Negative effect gradients emerged according to age (from 60.2 in the 15-44y/o group to 55.0 over $75 \mathrm{y} / \mathrm{o}$ ) and family economic difficulties from least to most difficulties (ranging from 61.7 to 54.9). Those who declared low social support had lower WEMWBS scores (44.0 vs 59.2, Cohen's $d=-1.54$ ). Perceived health status also yielded a negative gradient of WEMWBS scores, from 63.4 for excellent health to 46.1 for poor health. Small differences in effect sizes appeared when stratifying by sex: being student, employed or having a mental disorder had larger effect in men than in women. On the contrary, lack of autonomy had higher effect in women than in men (Cohen's $d=0.76$ and 0.64 , respectively).

Table 3 displays model fit and explained variance in block regression models. All blocks had impact on mental well-being. By block, socioeconomic factors explained $9.8 \%$ of mental well-being variance; relational factors explained $6.3 \%$, and lifestyle factors explained only $2.2 \%$. Health factor block had the most substantial contribution to mental well-being with $20.4 \%$ of explained variance, and perceived health status explained $16.3 \%$. Sequential block entry showed that, after adjusting by year of survey and demographic factors, the incremental contribution of socioeconomic factors was $7.8 \%$. Successive block contribution was: relational factors $4.4 \%$; lifestyle factors $0.1 \%$; health factors $10.0 \%$, and self-reported health $2.9 \%$. The full model with all variables explained $29.4 \%$ of mental well-being variance. Similar results were observed when stratifying by sex (results available upon request).

Table 4 includes regression coefficients for total, direct and indirect effects of individual variables adjusted by MSAS from DAG-1. Supplementary Figure 2 summarizes the variables used to build each model. As hypothesized, the largest effect sizes were those of health and relational factors. Low social support had a moderate association with well-being $\left(\right.$ eta $^{2}=6.3 \%$ ), implying 12 points less mental well-being. Self-reported health had the highest effect (eta ${ }^{2}=16.3 \%$ ) with a 10-point difference from excellent to poor health. Being dependent and having a mental disorder also implied lower well-being ( $\mathrm{eta}^{2}=10.6 \%$ and $13.4 \%$, respectively). Except for employment $\left(\mathrm{eta}^{2}=6.4 \%\right)$, demographic, socioeconomic and lifestyle factors showed low association with mental well-being.

Noticeably, there was no direct association between sex and mental well-being ( $\beta=-0.05$, SE 0.14). The direct effect of smoking habits was also negligible $\left(\mathrm{eta}^{2}=0.1 \%\right)$. Age, education, social class, social support, BMI, hours of sleep, mental disorder, lack of autonomy and perceived health status had higher effects in women than in men; the opposite was true in the case of employment status (results available upon request).

Figure 2a shows total and decomposed (direct and indirect) effects for variable categories on mental well-being. Interestingly, lower levels of well-being due to age were more explained by indirect rather than direct associations: middle-aged subjects (45-64y) presented lower direct scores $(\beta=1.24$, SE 0.33$)$ than the younger group $(\beta=1.33$, SE $0.36)$. Contrarily, for socioeconomic factors, direct effects represented about $50 \%$ of the total. In fact, the gradient in well-being according to economic difficulties was mostly direct. Regarding relational factors, $77.9 \%$ of the total effects came from direct effects. Mental disorders and lack of autonomy showed similar results.

Figure $2 \mathrm{~b}$ shows total effects (decomposed into direct and indirect effects) when health factors were removed from the DAG to study the contribution of health factors and selfperceived health on the indirect effects of each variable on mental well-being (see Supplementary Table 1 for comparison of direct and total effects when excluding health factors in the DAG-2 and Supplementary Figure 4 for their respective MSAS). The relative contribution of health factors varied across predictors. For example, health factors explained over $65 \%$ of the indirect effects of age on well-being and less than $10 \%$ of the indirect effect of education. Interestingly, health factors had lower indirect effects on well-being at higher levels of economic difficulties (values ranging from 30 to $50 \%$ ). Finally, health factors explained all the indirect effects of social support on well-being.

\section{Discussion}

In this study we analysed the association of individual factors and mental well-being. Three main findings emerged: first, differences in the distribution of mental well-being according to gender and age were mostly due to indirect effects, which suggest social inequalities, given that other factors mediate their relationship; second, health factors and self-perceived health were highly associated to mental well-being; third, the lack of perceived functional social support is itself a critical risk factor for lower mental well-being. A novelty of this study is the decomposition of effects for each hypothesis of exposure-outcome. This 
Table 2 Distribution of sample characteristics $(N, \%)$ and description of WEMWBS scores (mean, SE) across categories of study variables

\begin{tabular}{|c|c|c|c|c|c|c|c|}
\hline \multirow[t]{2}{*}{ Variable } & \multirow[t]{2}{*}{ Category } & \multicolumn{2}{|c|}{ Total $\left(N^{\#}=13,632\right)$} & \multicolumn{2}{|c|}{ Women $\left(N^{\#}=6814\right)$} & \multicolumn{2}{|c|}{$\operatorname{Men}\left(N^{\#}=6818\right)$} \\
\hline & & $N^{\#}(\%)$ & $\begin{array}{l}\text { WEMWBS score } \\
\text { Mean* (SE) }\end{array}$ & $N^{\#}(\%)$ & $\begin{array}{l}\text { WEMWBS score } \\
\text { Mean* (SE) }\end{array}$ & $N^{\#}(\%)$ & $\begin{array}{l}\text { WEMWBS score } \\
\text { Mean* (SE) }\end{array}$ \\
\hline \multirow[t]{2}{*}{ Sex } & Men & $6818(49.1)$ & $59.5(0.12)$ & & & & \\
\hline & Women & $6814(50.9)$ & $58.2(0.13)$ & & & & \\
\hline \multirow[t]{4}{*}{ Age (years) } & $15-44$ & $6372(48.5)$ & $60.2(0.11)$ & $3113(46.5)$ & $59.9(0.16)$ & $3259(50.7)$ & $60.5(0.15)$ \\
\hline & $45-64$ & $4311(31.2)$ & $58.3(0.16)$ & $2141(30.9)$ & $57.6(0.23)$ & $2170(31.6)$ & $59.1(0.21)$ \\
\hline & $65-74$ & $1377(10.5)$ & $57.6(0.30)$ & $720(11.1)$ & $57.0(0.43)$ & $657(10.0)$ & $58.4(0.41)$ \\
\hline & $\geq 75$ & $1572(9.7)$ & $55.0(0.31)$ & $840(11.5)$ & $54.4(0.42)$ & $732(7.8)$ & $56.0(0.42)$ \\
\hline \multirow[t]{3}{*}{ Country of origin } & Spain & $11,406(83.7)$ & $58.7(0.10)$ & $5700(84.0)$ & $58.1(0.14)$ & $5706(83.3)$ & $59.4(0.13)$ \\
\hline & High income & 287 (1.9) & $60.0(0.50)$ & $143(1.7)$ & $59.8(0.68)$ & $144(2.1)$ & $60.2(0.73)$ \\
\hline & Other & $1936(14.4)$ & $59.6(0.22)$ & $970(14.3)$ & $59.0(0.32)$ & $966(14.6)$ & $60.2(0.30)$ \\
\hline \multirow[t]{3}{*}{ Educational level } & Up to Primary & $3085(21.3)$ & $56.2(0.21)$ & $1588(22.8)$ & $55.5(0.30)$ & $1497(19.7)$ & $57.0(0.30)$ \\
\hline & Secondary & $7926(57.8)$ & $59.3(0.11)$ & $3808(55.2)$ & $58.7(0.17)$ & $4118(60.6)$ & $59.9(0.15)$ \\
\hline & Higher & $2615(20.8)$ & $60.4(0.16)$ & $1415(22.0)$ & $60.0(0.23)$ & $1200(19.7)$ & $60.9(0.21)$ \\
\hline \multirow[t]{4}{*}{ Social class } & I & $2623(20.5)$ & $60.1(0.16)$ & $1274(20.2)$ & $59.8(0.23)$ & 1349 (20.9) & $60.5(0.22)$ \\
\hline & II & $2256(17.3)$ & $59.2(0.20)$ & $1207(18.2)$ & $58.7(0.30)$ & 1049 (16.4) & $59.7(0.26)$ \\
\hline & III & $8304(58.8)$ & $58.5(0.12)$ & 4005 (56.9) & $57.8(0.17)$ & $4299(60.8)$ & $59.2(0.16)$ \\
\hline & Has never worked & $294(2.0)$ & $54.1(0.77)$ & $236(3.1)$ & $53.3(0.80)$ & $58(0.9)$ & $57.1(1.95)$ \\
\hline \multirow[t]{6}{*}{ Employment status } & Student & $1150(8.7)$ & $61.0(0.24)$ & $571(8.3)$ & $60.4(0.36)$ & $579(9.0)$ & $61.5(0.32)$ \\
\hline & Employed & $6857(50.4)$ & $60.4(0.10)$ & $3158(46.0)$ & $59.8(0.16)$ & $3699(55.0)$ & $60.9(0.13)$ \\
\hline & Unemployed & $1330(10.7)$ & $57.1(0.29)$ & $551(9.0)$ & $57.0(0.45)$ & 779 (12.6) & $57.1(0.38)$ \\
\hline & Housework & $1401(10.3)$ & $56.9(0.30)$ & $1401(20.1)$ & $56.9(0.30)$ & $0(0.0)$ & \\
\hline & Retired & $2263(15.1)$ & $57.5(0.23)$ & $842(12.2)$ & $56.7(0.39)$ & $1421(18.1)$ & $58.1(0.28)$ \\
\hline & Other conditions & $592(4.6)$ & $51.7(0.55)$ & $254(3.8)$ & $50.0(0.84)$ & $338(5.4)$ & $53.0(0.72)$ \\
\hline \multirow{6}{*}{$\begin{array}{l}\text { Family economic } \\
\text { difficulties to make } \\
\text { monthly ends meet }\end{array}$} & Great difficulty & $851(7.3)$ & $54.9(0.44)$ & $433(7.4)$ & $54.3(0.62)$ & $418(7.1)$ & $55.6(0.62)$ \\
\hline & Difficulty & $1603(13.3)$ & $56.5(0.27)$ & $851(14.0)$ & $55.7(0.38)$ & $752(12.6)$ & $57.5(0.38)$ \\
\hline & Some difficulty & $3216(24.9)$ & $58.4(0.18)$ & $1644(25.4)$ & $57.9(0.25)$ & $1572(24.4)$ & $58.9(0.24)$ \\
\hline & Some ease & $5533(37.7)$ & $59.7(0.12)$ & $2687(36.6)$ & $59.1(0.17)$ & $2846(38.8)$ & $60.3(0.15)$ \\
\hline & Ease & $2135(14.8)$ & $61.1(0.19)$ & $1071(14.7)$ & $60.4(0.28)$ & $1064(14.8)$ & $61.9(0.25)$ \\
\hline & Great ease & $294(2.1)$ & $61.7(0.54)$ & $128(1.9)$ & $61.6(0.88)$ & $166(2.4)$ & $61.8(0.66)$ \\
\hline \multirow[t]{2}{*}{ Social support } & Low & $263(2.1)$ & $44.0(0.81)$ & $157(2.5)$ & $43.3(1.05)$ & $106(1.7)$ & $45.1(1.26)$ \\
\hline & Adequate & 13,369 (97.9) & $59.2(0.08)$ & 6657 (97.5) & $58.6(0.12)$ & $6712(98.3)$ & $59.8(0.11)$ \\
\hline \multirow[t]{4}{*}{ BMI } & Underweight & $330(2.4)$ & $58.4(0.60)$ & $256(3.7)$ & $58.6(0.68)$ & $74(1.1)$ & $57.7(1.29)$ \\
\hline & Normal weight & 6426 (47.6) & $59.6(0.12)$ & $3537(52.1)$ & $59.1(0.16)$ & 2889 (43.0) & $60.2(0.17)$ \\
\hline & Overweight & $4642(33.7)$ & $58.8(0.15)$ & 1849 (26.9) & $57.8(0.24)$ & $2793(40.7)$ & $59.5(0.18)$ \\
\hline & Obesity & $2041(14.7)$ & $57.0(0.25)$ & 1035 (14.9) & $56.2(0.36)$ & 1006 (14.6) & $58.0(0.34)$ \\
\hline \multirow[t]{3}{*}{ Hours of sleep } & $<6 \mathrm{~h}$ & $1064(8.4)$ & $55.6(0.37)$ & $619(9.7)$ & $55.0(0.48)$ & $445(7.0)$ & $56.4(0.57)$ \\
\hline & $6-8 \mathrm{~h}$ & $11,231(82.6)$ & $59.3(0.09)$ & 5549 (81.4) & $58.7(0.13)$ & $5682(83.8)$ & $59.9(0.12)$ \\
\hline & $>8 \mathrm{~h}$ & $1320(8.9)$ & $58.1(0.33)$ & $635(8.7)$ & $57.4(0.50)$ & $685(9.1)$ & $58.7(0.44)$ \\
\hline \multirow[t]{3}{*}{ Smoking status } & Current smoker & 3488 (25.5) & $58.6(0.17)$ & 1419 (20.7) & $57.8(0.29)$ & 2069 (30.5) & $59.1(0.22)$ \\
\hline & Ex-smoker & 2551 (19.5) & $59.3(0.20)$ & 897 (14.4) & $59.5(0.31)$ & $1654(24.8)$ & $59.2(0.25)$ \\
\hline & Non-smoker & $7593(55.0)$ & $58.9(0.12)$ & $4498(65.0)$ & $58.1(0.16)$ & 3095 (44.7) & $60.0(0.16)$ \\
\hline \multirow[t]{2}{*}{ Mental disorder } & Yes & $2170(17.0)$ & $51.8(0.27)$ & $1484(22.9)$ & $52.2(0.32)$ & $686(10.9)$ & $51.0(0.48)$ \\
\hline & No & $11,462(83.0)$ & $60.3(0.08)$ & $5330(77.1)$ & $60.0(0.12)$ & $6132(89.1)$ & $60.6(0.11)$ \\
\hline \multirow[t]{2}{*}{ Physical disorder } & Yes & 8798 (63.9) & $57.6(0.12)$ & 4847 (70.6) & $57.2(0.16)$ & 3951 (56.9) & $58.2(0.17)$ \\
\hline & No & $4834(36.1)$ & $61.0(0.11)$ & 1967 (29.4) & $60.6(0.17)$ & $2867(43.1)$ & $61.3(0.15)$ \\
\hline \multirow[t]{2}{*}{ Lack of autonomy } & No & $12,525(92.0)$ & $59.7(0.08)$ & $6160(90.1)$ & $59.3(0.12)$ & $6365(94.0)$ & $60.1(0.11)$ \\
\hline & Yes & $1107(8.0)$ & $49.3(0.39)$ & $654(9.9)$ & $48.3(0.50)$ & $453(6.0)$ & $51.0(0.62)$ \\
\hline
\end{tabular}


Table 2 (continued)

\begin{tabular}{|c|c|c|c|c|c|c|c|}
\hline \multirow[t]{2}{*}{ Variable } & \multirow[t]{2}{*}{ Category } & \multicolumn{2}{|c|}{ Total $\left(N^{\#}=13,632\right)$} & \multicolumn{2}{|c|}{ Women $\left(N^{\#}=6814\right)$} & \multicolumn{2}{|c|}{$\operatorname{Men}\left(N^{\#}=6818\right)$} \\
\hline & & $N^{\#}(\%)$ & $\begin{array}{l}\text { WEMWBS score } \\
\text { Mean* (SE) }\end{array}$ & $N^{\#}(\%)$ & $\begin{array}{l}\text { WEMWBS score } \\
\text { Mean* (SE) }\end{array}$ & $N^{\#}(\%)$ & $\begin{array}{l}\text { WEMWBS score } \\
\text { Mean* (SE) }\end{array}$ \\
\hline \multirow[t]{5}{*}{ Perceived health status } & Excellent & $1044(8.2)$ & $63.4(0.21)$ & $439(6.8)$ & $63.2(0.33)$ & $605(9.6)$ & $63.5(0.27)$ \\
\hline & Very good & $4410(32.4)$ & $60.7(0.11)$ & $2122(30.8)$ & $60.4(0.17)$ & $2288(34.0)$ & $60.9(0.16)$ \\
\hline & Good & $5678(40.9)$ & $59.4(0.12)$ & $2848(41.2)$ & $59.1(0.17)$ & $2830(40.6)$ & $59.8(0.17)$ \\
\hline & Fair & $2032(15.0)$ & $54.0(0.26)$ & $1127(17.0)$ & $53.4(0.36)$ & $905(13.0)$ & $54.8(0.38)$ \\
\hline & Poor & $467(3.5)$ & $46.1(0.61)$ & $277(4.2)$ & $45.5(0.78)$ & $190(2.8)$ & $47.1(0.95)$ \\
\hline
\end{tabular}

$B M I$ body mass index, $N$ number, $S E$ standard error

*All variables have a significant effect on mental well-being (one-way ANOVA; $p<0.05$ ) after the Benjamini-Hochberg correction with false discovery rate 0.05

${ }^{\#}$ Unweighted $N$

Table 3 Model fit and \% explained variance by (a) individual blocks of factors and (b) incremental block effects when blocks entered sequentially

\begin{tabular}{|c|c|c|c|}
\hline & \multirow{2}{*}{$\begin{array}{l}\text { Block effect } \\
\text { Explained variance }(\%)\end{array}$} & \multicolumn{2}{|c|}{ Incremental block effects } \\
\hline & & $\begin{array}{l}\text { Total explained vari- } \\
\text { ance }(\%)\end{array}$ & $\begin{array}{l}\text { Increase in } \\
\text { explained vari- } \\
\text { ance }(\%)\end{array}$ \\
\hline Year of survey & 0.4 & 0.4 & - \\
\hline Demographic factors & 3.8 & 4.2 & 3.8 \\
\hline Socioeconomic factors & 9.8 & 12.0 & 7.8 \\
\hline Relational factors & 6.3 & 16.4 & 4.4 \\
\hline Lifestyle factors & 2.2 & 16.5 & 0.1 \\
\hline Health factors & 20.4 & 26.5 & 10.0 \\
\hline Perceived health* & 16.3 & 29.4 & 2.9 \\
\hline
\end{tabular}

Each model contained all variables within each block

All models are significant ( $F$ statistic $p<0.001)$. The $\%$ variance is computed as, adjusted $R^{2 * 100}(\%)$

*The final model with the seven blocks factors contains all studied variables approach may add valuable information to the study of health disparities and social determinants of health [44].

We found that men had a marginally higher mental well-being than women, in line with previous studies based on WEMWBS [22, 45, 46]. Most of sex association was indirect, via socioeconomic and health factors. This is in contrast with the consistent findings on sex differences in mental health and psychopathology [47, 48]. Our results may imply that sex impacts differently in positive and negative mental states. A similar result was found for age: increasing age was negatively associated with mental well-being, but the effect was mostly indirect and mediated by health factors. Also, age and well-being associations were linear, in contrast with previous studies reporting a $\mathrm{U}$-shape relation, in which young and the elderly people present higher well-being than middle-aged adults [49, 50]. Additional analyses are needed to test potential quadratic effects of age on mental well-being in the population.
Our results revealed associations between economic conditions and mental well-being. Unemployment was a substantial risk factor for lower mental well-being, and a distinct negative gradient in mental well-being appeared according to family economic difficulties. Stewart-Brown et al. [22], found that the group with higher economic resource presented better odds of higher mental well-being; however, no differences existed among other groups. In our study, economic effects were direct and had no sizeable mediating role. However, additional analyses showed that, as economic difficulties increased, health factors contributed less to the indirect effect on well-being (see Supplementary Table 1). This result is most relevant when considering that a direct effect of socioeconomic factors on mental well-being in groups with economic difficulties would imply a source of social inequality. Such result aligns with previous research: job type and job context characteristics may determine the relationship between work, income and well-being [51, 52]. 


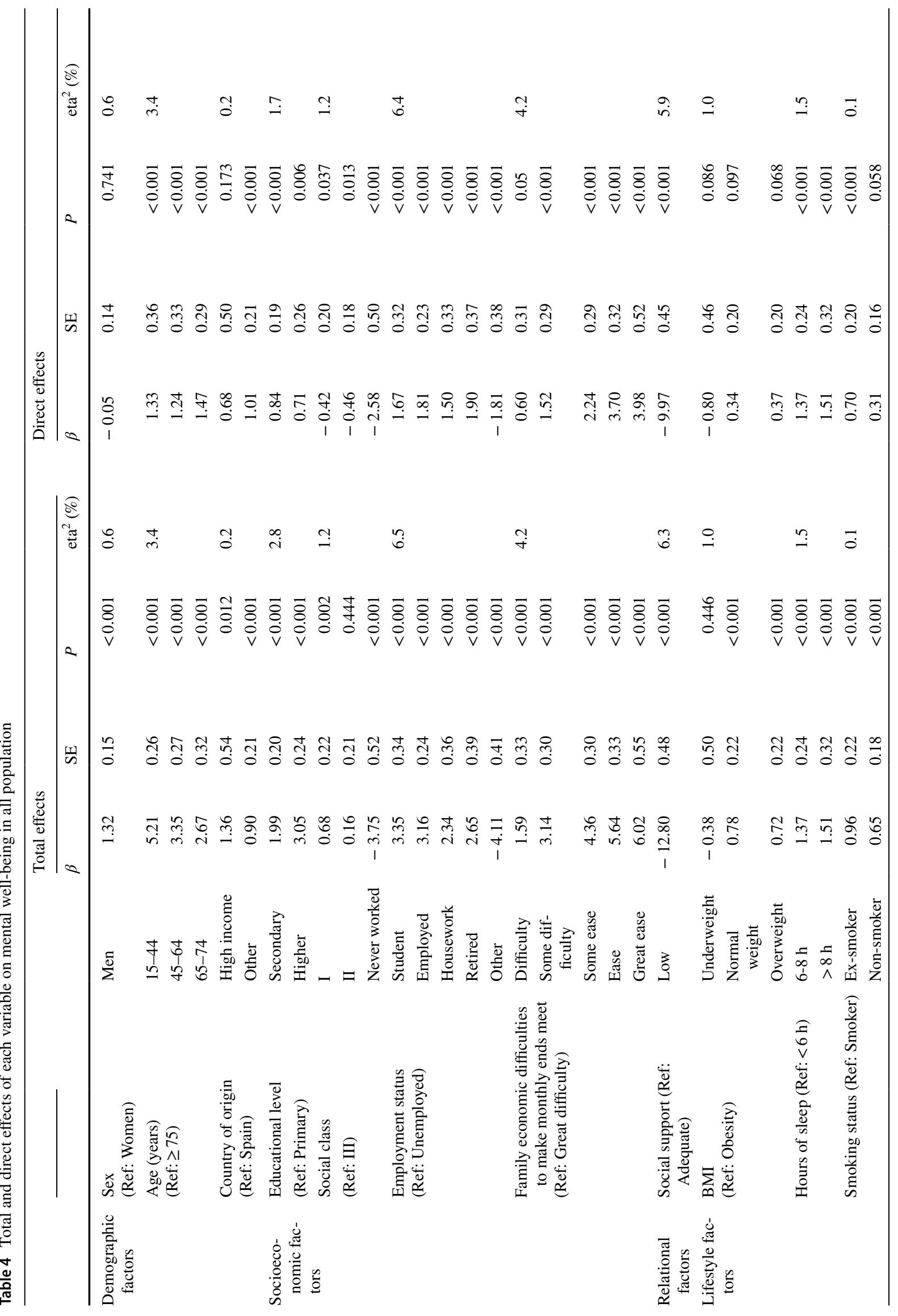




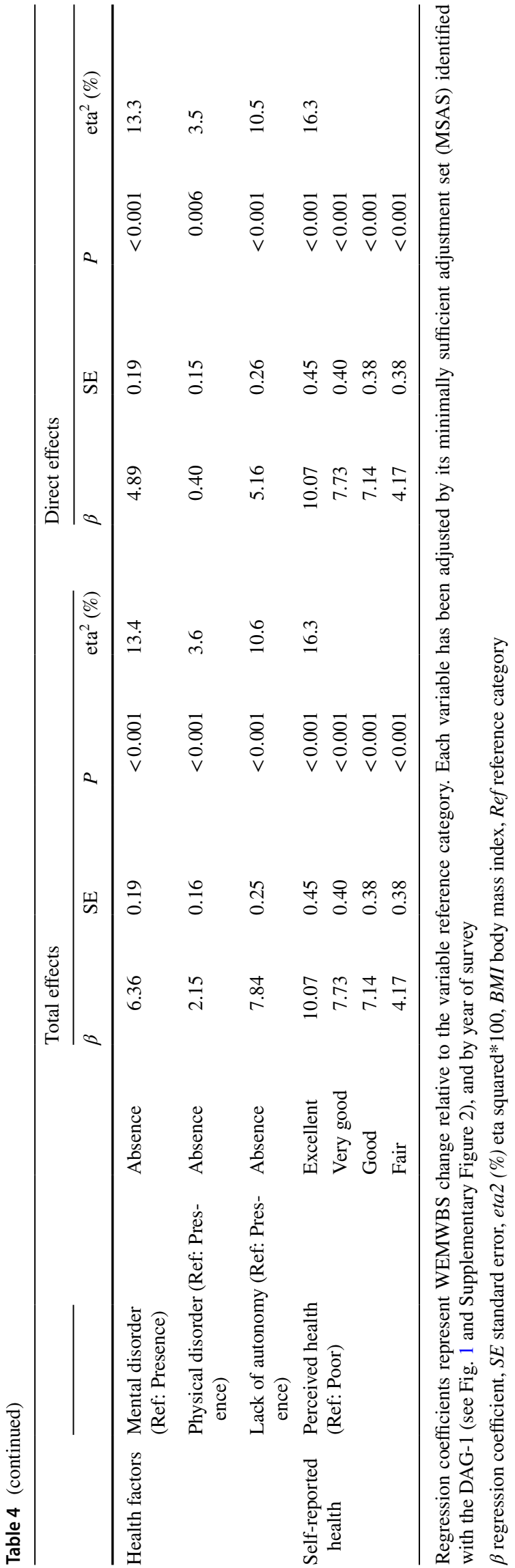

Literature also points at less frequent health-oriented behaviours in persons with limited resources, which may contribute to social differences in social well-being [53].

In our study, low functional social support played a key role, and had the most substantial effect in mental wellbeing scores among all groups. Our findings add to the existing evidence that social support plays a decisive role in the maintenance of psychological well-being and that poor social relationship negatively impact mental health $[14,54,55]$. Moreover, our results suggest that the most important effects of social support on well-being are direct, and their small indirect effect go through health factors. Literature abounds in social support interventions on different outcomes and specific groups [56, 57]. Our findings agree with previous studies showing a strong relationship between physical, psychological health and subjective wellbeing [17]. Under the model, health factors were the most important contributors to mental well-being. There was also a strong association between self-reported health and mental well-being, those reporting better health also showed higher levels of mental well-being. Qualitative studies show that health is at the core of what constitutes well-being [20]. Suffering from a mental disorder had a huge direct association with well-being, which has been found in previous studies on the relationship between WEMWBS and mental illness [58]. The debate on wether well-being or mental illness are part of the same dual continuum or separate constructs is still open [59]. Our model cannot distinguish whether mental wellbeing and mental illness are part of the same construct or its outcome. Yet, under our causal assumptions, well-being comes after health factors, so promoting population health may be a way of promoting well-being.

As hypothesized, when decomposing variable effects on well-being through health variables, we found they mediated the associations. This result matches well-known models of disability where it comes as a consequence of health $[19,60$, 61]. In spite of potential reverse causality effects between mental well-being and health, our results add to the evidence supporting the sensitivity of mental well-being as a health outcome. In our study, WEMWBS was sensitive to a variety of socioeconomic, relational and health factors. Mental wellbeing overcomes the disadvantages of instruments designed to be sensitive in the population fraction with mental health problems. This approach potentially capture changes in wellbeing that otherwise would have gone unnoticed [21, 62]. Such relationships must be explored in future research, ideally in longitudinal studies.

Our results must be interpreted in light of some limitations. Firstly, the temporal ambiguity entailed by crosssectional designs regarding causality involves that results are as correct as DAG assumptions. It is worth noting that other models may be devised, and that we are not proposing a theoretical framework of mental well-being. Our DAG 

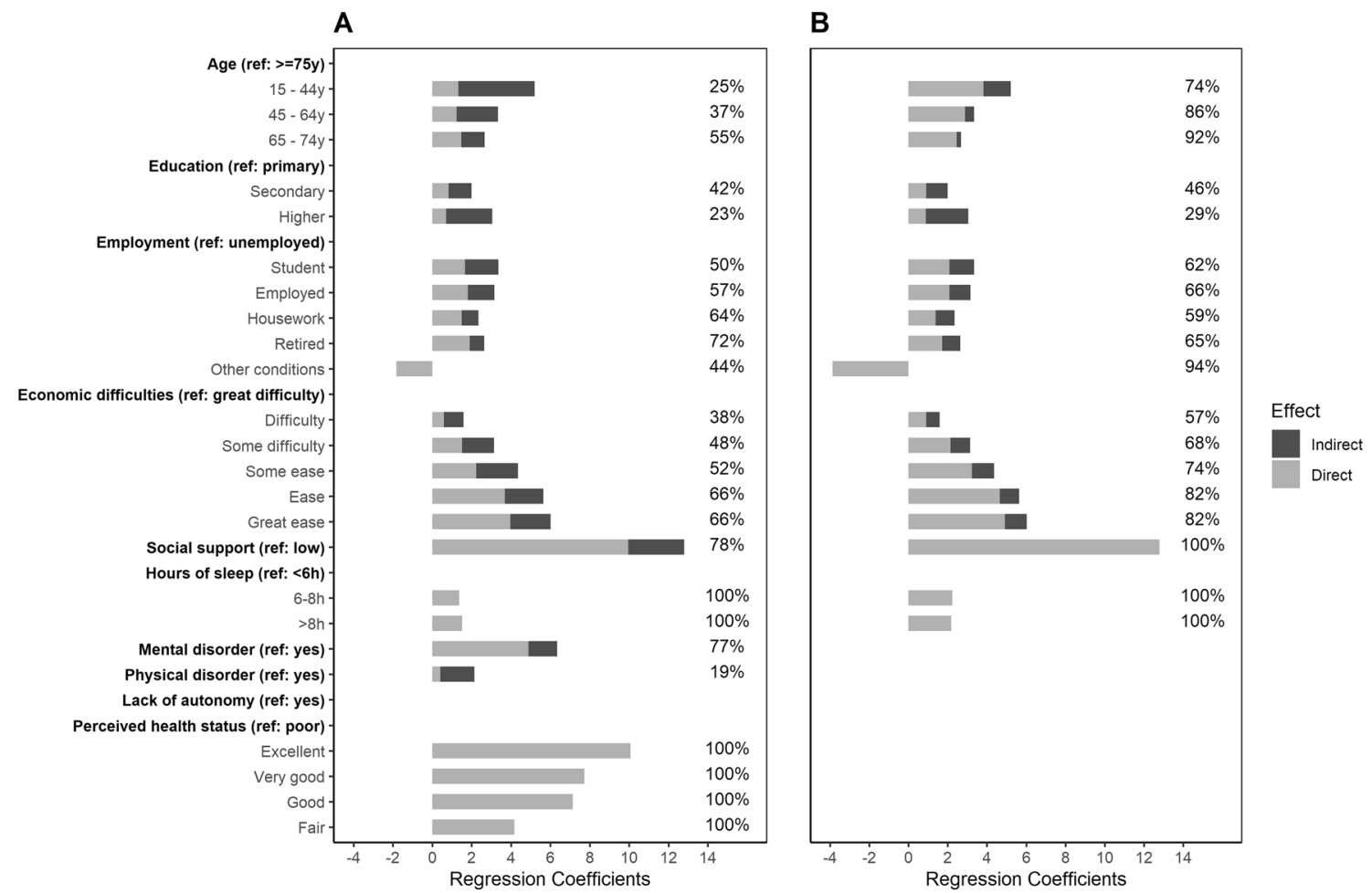

Fig. 2 Variable total effects, as regression coefficient value, decomposed into direct (light area) and indirect (dark area). Values adjusted by each variable's minimally sufficient adjustment set (MSAS) a from DAG-1 that includes health factors; and b from DAG-2 that excludes health factors. Values over bars represent the percentage of direct effects over total effects. Only variables significantly associated with mental well-being are represented $(P<0.05)$. (Color figure online) just intends to systematize [63] and make transparent our assumptions on exposures-outcome relationships. As of date, no theoretical framework exists on mental well-being to guide DAG-building, so we based our model on the widespread and commonly accepted WHO model of determinants of health and disability $[19,60,61]$. Traditional methods based on fit criteria (e.g. $R^{2}$ or Akaike information criterion) would take the model as a whole, thus ignoring directionality in the relationships. Secondly, conceptually relevant variables were not available (e.g. social participation [23] or dispositional traits such personality or character variables) [64]). Personality is itself a most relevant variable in behaviour analyses and would indeed affect well-being outcomes. However, mental and physical health are also affected by such variables, so that they might encompass these effects up to a certain point. Finally, the ESCA survey assesses lifetime presence of disorders, so their reporting can either be affected by recall bias or absent at the time of the interview, yielding results which are likely to average both of these influences.

However, this study is not without strengths: its representativeness, sample size, and various variables make it comprehensive and able to detect small effects. Also, the use of MSAS disconnect irrelevant pathways from the multivariable analysis, reducing noise parameter estimates [65]. We have also tested separate models of direct and indirect effects for each exposure-outcome hypothesis, so that results inform of pathways that can be intervened directly on the variable or averted at some point along causal chains. Future models using this kind of effect decomposition may help to refine the study of modifiable effects of health disparities and social determinants of health.

\section{Conclusions}

This study identified a variety of factors associated with the levels of mental well-being, ranging from structural factors such as gender, age and employment, to more proximal factors such as social support and health factors. These results are consistent with previous studies focussing on disability and disease. Our results support that mental well-being, and especially WEMWBS, could be an essential tool for monitoring population health and general well-being. The focus on positive mental health offers an opportunity to expand research on aspects of promotion rather than prevention. Finally, policies aimed at reducing social inequalities are also required to promote the well-being of the population. 
Supplementary Information The online version contains supplementary material available at https://doi.org/10.1007/s11136-021-02813-5.

Author contributions JC, AM, JC, AS were responsible for data acquisition. GV, CGF, JA were responsible of study conceptualization and design. NSD analysed the data. IA contributed analysis tools. PM, $\mathrm{BP}, \mathrm{DM}$ and NS, made substantial contributions in data interpretation. NSD, GV, CGF, JA, wrote the first draft. All authors provided critical revisions. All authors read and approved the submitted manuscript.

Funding The study has been funded by grant from Generalitat de Catalunya (2017 SGR 452) and by ISCIII-FEDER (PI19/00109). NSD was recipient of a predoctoral fellowship 2021 FI_B 00104 from the DIUEAGAUR of the "Generalitat de Catalunya". The authors are indebted to the Department of Health of Generalitat de Catalunya for providing raw data from the ESCA dataset for the analysis.

Data availability The raw data of this study are available from Department of Health of Generalitat de Catalunya. Restrictions apply to the availability of these data, which were used under license for this study. Data that support the findings of this study are available from the corresponding author [GV] with the permission of Department of Health of Generalitat de Catalunya.

Code availability The $\mathrm{R}$ code is available upon request from the corresponding author.

\section{Declarations}

Conflict of interest The authors declare that they have no conflict of interest.

Ethical approval Data from the present cross-sectional study were obtained from the Catalan Health Interview Survey (ESCA) that has the rank of official statistics carried out by the Government of the Catalonia region, and it must ensure the confidentiality of the data (Law 23/1998, December 30, of statistics of Catalonia). The content of the ESCA and the whole interview process follows the European Statistics Code of Practice adopted by the European Statistical System Committee. ESCA anonymous microdata can be requested for scientific research purposes. The present project has been approved by the Drug Research Ethical Committee of the Parc de Salut Mar (\#2019/8650/I).

Open Access This article is licensed under a Creative Commons Attribution 4.0 International License, which permits use, sharing, adaptation, distribution and reproduction in any medium or format, as long as you give appropriate credit to the original author(s) and the source, provide a link to the Creative Commons licence, and indicate if changes were made. The images or other third party material in this article are included in the article's Creative Commons licence, unless indicated otherwise in a credit line to the material. If material is not included in the article's Creative Commons licence and your intended use is not permitted by statutory regulation or exceeds the permitted use, you will need to obtain permission directly from the copyright holder. To view a copy of this licence, visit http://creativecommons.org/licenses/by/4.0/.

\section{References}

1. OECD Publishing. (2013). OECD Guidelines on Measuring Subjective Well-being.
2. New Economics Foundation. (2012). Measuring Well-being A guide for practitioners.

3. WHO. (2018). Mental health: Strengthening our response. Retrieved November 14, 2018, from http://www.who.int/newsroom/fact-sheets/detail/mental-health-strengthening-our-response

4. Ryan, R. M., \& Deci, E. L. (2001). On happiness and human potentials: A review of research on hedonic and eudaimonic wellbeing. Annual Review of Psychology, 52(1), 141-166. https://doi. org/10.1146/annurev.psych.52.1.141

5. Huppert, F. A. (2009). Psychological well-being: Evidence regarding its causes and consequences. Applied Psychology: Health and Well-Being, 1(2), 137-164. https://doi.org/10.1111/j.1758-0854. 2009.01008.x

6. Chida, Y., \& Steptoe, A. (2008). Positive psychological well-being and mortality: A quantitative review of prospective observational studies. Psychosomatic Medicine, 70, 741-756. https://doi.org/10. 1097/PSY.0b013e31818105ba

7. CDC. (2018). Well-being concepts. Retrieved November 15, 2018, from https://www.cdc.gov/hrqol/wellbeing.htm

8. Mehta, N., Croudace, T., \& Davies, S. C. (2015). Public mental health: evidenced-based priorities. The Lancet, 385, 1472-1475. https://doi.org/10.1016/S0140-6736(14)61400-8

9. Forsman, A. K., Wahlbeck, K., Aarø, L. E., Alonso, J., Barry, M. M., Brunn, M., ... Sant, F. (2015). Research priorities for public mental health in Europe: Recommendations of the ROAMER project. European Journal of Public Health, 25(2), 249-254. http:// doi.org/https://doi.org/10.1093/eurpub/cku232

10. World Health Organization. (2001). International classification of functioning, disability and health (ICF). Geneva: World Health Organization.

11. Berkman, L. F., Kawachi, I., \& Glymour, M. M. (2014). Social epidemiology (2nd ed.). New York: Oxford University Press.

12. Barry, M. M. (2009). Addressing the determinants of positive mental health: concepts, evidence and practice. International Journal of Mental Health Promotion, 11(3), 4-7.

13. Wootton, R. E., Lawn, R. B., Millard, L. A. C., Davies, N. M., Taylor, A. E., Munafò, M. R., ... Haworth, C. M. A. (2018). Evaluation of the causal effects between subjective wellbeing and cardiometabolic health: Mendelian randomisation study. BMJ (Online). http://doi.org/https://doi.org/10.1136/bmj.k3788

14. Tough, H., Siegrist, J., \& Fekete, C. (2017). Social relationships, mental health and wellbeing in physical disability: A systematic review. BMC Public Health, 17(1), 414. https://doi.org/10.1186/ s12889-017-4308-6

15. Lamu, A. N., \& Olsen, J. A. (2016). The relative importance of health, income and social relations for subjective well-being: An integrative analysis. Social Science and Medicine, 152, 176-185. https://doi.org/10.1016/j.socscimed.2016.01.046

16. Binder, M., \& Coad, A. (2013). "I'm afraid I have bad news for you." Estimating the impact of different health impairments on subjective well-being. Social Science and Medicine, 87, 155-167. https://doi.org/10.1016/j.socscimed.2013.03.025

17. Dolan, P., Peasgood, T., \& White, M. (2008). Do we really know what makes us happy? A review of the economic literature on the factors associated with subjective well-being. Journal of Economic Psychology, 29(1), 94-122. https://doi.org/10.1016/J.JOEP. 2007.09.001

18. Shields, M. A., \& Price, S. W. (2005). Exploring the economic and social determinants of psychological well-being and perceived social support in England. Journal of the Royal Statistical Society: Series A (Statistics in Society), 168(3), 513-537. https://doi.org/ 10.1111/j.1467-985X.2005.00361.x

19. Alonso, J., Vilagut, G., Adroher, N. D., Chatterji, S., He, Y., Andrade, L. H., ... Kessler, R. C. (2013). Disability mediates the impact of common conditions on perceived health. PLoS ONE, 
8(6), e65858. http://doi.org/https://doi.org/10.1371/journal.pone. 0065858

20. Simon, J. G., De Boer, J. B., Joung, I. M. A., Bosma, H., \& Mackenbach, J. P. (2005). How is your health in general? A qualitative study on self-assessed health. European Journal of Public Health, 15(2), 200-208. https://doi.org/10.1093/eurpub/cki102

21. Tennant, R., Hiller, L., Fishwick, R., Platt, S., Joseph, S., Weich, S., ... Stewart-Brown, S. (2007). The Warwick-Dinburgh mental well-being scale (WEMWBS): Development and UK validation. Health and Quality of Life Outcomes, 5(63), 1-13. http://doi. org/https://doi.org/10.1186/1477-7525-5-63

22. Stewart-Brown, S., Samaraweera, P. C., Taggart, F., Kandala, N. B., \& Stranges, S. (2015). Socioeconomic gradients and mental health: Implications for public health. British Journal of Psychiatry, 206(6), 461-465. https://doi.org/10.1192/bjp.bp.114. 147280

23. Santini, Z. I., Stougaard, S., Koyanagi, A., Ersbøll, A. K., Nielsen, L., Hinrichsen, C., ... Koushede, V. (2020). Predictors of high and low mental well-being and common mental disorders: Findings from a Danish population-based study. European Journal of Public Health. http://doi.org/https://doi.org/10.1093/ eurpub/ckaa021

24. Direcció General de Planificació en Salut. (2016). Document tècnic de l'Enquesta de salut de Catalunya (ESCA) Període 2011-2016. Barcelona. Retrieved from https://salutweb.gencat. cat/web/.content/_departament/estadistiques-sanitaries/enque stes/Enquesta-de-salut-de-Catalunya/documents-tecnics/docum ent_tecnic_esca_2011_2016.pdf

25. Castellví, P., Forero, C. G., Codony, M., Vilagut, G., Brugulat, P., Medina, A., ... Alonso, J. (2014). The Spanish version of the Warwick-Edinburgh mental well-being scale (WEMWBS) is valid for use in the general population. Quality of Life Research, 23(3), 857-868. http://doi.org/https://doi.org/10. 1007/s11136-013-0513-7

26. López, M. A., Gabilondo, A., Codony, M., García-Forero, C., Vilagut, G., Castellví, P., ... Alonso, J. (2013). Adaptation into Spanish of the Warwick-Edinburgh mental well-being scale (WEMWBS) and preliminary validation in a student sample. Quality of Life Research, 22(5), 1099-1104. http://doi. org/https://doi.org/10.1007/s11136-012-0238-z

27. OECD. (2019). Country Classification-As of 14 August 2019. Retrieved June 17, 2020, from http://www.oecd.org/trade/topics/export-credits/arrangement-and-sector-understandings/finan cing-terms-and-conditions/

28. Domingo-Salvany, A., Bacigalupe, A., Carrasco, J. M., Espelt, A., Ferrando, J., \& Borrell, C. (2013). Proposals for social class classification based on the Spanish National Classification of Occupations 2011 using neo-Weberian and neo-Marxist approaches. Gaceta Sanitaria, 27(3), 263-272. https://doi.org/ 10.1016/j.gaceta.2012.12.009

29. Broadhead, W., Gehlbach, S., Degruy, F., \& Kaplan, B. (1988). The DUKE-UNC functional social support questionnaire: Measurement of social support in family medicine patients. Medical Care, 26(7), 709-723. https://doi.org/10.1097/00005650-19880 7000-00006

30. Bellón Saameño, J., Delgado Sánchez, A., Luna del Castillo, J. D., \& Lardelli Claret, P. (1996). Validity and reliability of the Duke-UNC-11 questionnaire of functional social support. Atención Primaria, 18(4), 153-3, 158-63.

31. Benjamini, Y., \& Hochberg, Y. (1995). Controlling the false discovery rate: A practical and powerful approach to multiple testing. Journal of the Royal Statistical Society. Series B (Methodological). WileyRoyal Statistical Society. http://doi. org/https://doi.org/10.2307/2346101

32. Cohen, J. (1992). A power primer. Psychological Bulletin, 112(1), 155-159. https://doi.org/10.1037//0033-2909.112.1.155
33. Sawilowsky, S. S. (2009). New effect size rules of thumb. Journal of Modern Applied Statistical Methods, 8(2), 597-599.

34. Cohen, J. (1988). Statistical power analysis for the behavioral sciences. Statistical Power Analysis for the Behavioral Sciences. https://doi.org/10.1234/12345678

35. Schisterman, E. F., Cole, S. R., \& Platt, R. W. (2009). Overadjustment bias and unnecessary adjustment in epidemiologic studies. Epidemiology, 20(4), 488-495. https://doi.org/10.1097/ EDE.0b013e3181a819a1.Overadjustment

36. Hernán, M., \& Robins, J. (2020). Causal inference: What if. Boca Raton: Chapman \& Hall/CRC.

37. Pearl, J. (2009). Causality. Cambridge: Cambridge University Press. https://doi.org/10.1017/CBO9780511803161

38. Van Der ZanderLis̈kiewiczTextor, B. M. J. (2014). Constructing separators and adjustment sets in ancestral graphs. CEUR Workshop Proceedings, 1274, 11-23.

39. Perković, E., Textor, J., Kalisch, M., \& Maathuis, M. H. (2015). A complete generalized adjustment criterion. In Proceedings of the 31st conference of uncertainty in artificial intelligence (UAI) 2015 (pp. 682-691).

40. Knüppel, S., \& Stang, A. (2010). DAG program: Identifying minimal sufficient adjustment sets. Epidemiology, 21(1), 159. https:// doi.org/10.1097/EDE.0b013e3181c307ce

41. Textor, J., Hardt, J., \& Knüppel, S. (2011). DAGitty: A graphical tool for analyzing causal diagrams. Epidemiology, 22(5), 745. https://doi.org/10.1097/EDE.0b013e318225c2be

42. StataCorp. (2013). Stata Statistical Software: Release 13. College Station: TX: StataCorp LP.

43. R Core Team. (2014). R: a language and environment for statistical computing. $R$ Foundation for Statistical Computing. Vienna, Austria.

44. Glymour, M. M., \& Spiegelman, D. (2017). Evaluating public health interventions: 5. Causal inference in public health research-Do sex, race, and biological factors cause health outcomes? American Journal of Public Health, 107(1), 81-85. https://doi.org/10.2105/AJPH.2016.303539

45. Gale, C. R., Cooper, R., Craig, L., Elliott, J., Kuh, D., Richards, M., ... Deary, I. J. (2012). Cognitive function in childhood and lifetime cognitive change in relation to mental wellbeing in four cohorts of older people. PloS ONE, 7(9), e44860. http://doi. org/https://doi.org/10.1371/journal.pone.0044860

46. Fat, L. N., Scholes, S., Boniface, S., Mindell, J., \& Stewart-Brown, S. (2017). Evaluating and establishing national norms for mental wellbeing using the short Warwick-Edinburgh mental well-being scale (SWEMWBS): Findings from the Health Survey for England. Quality of Life Research, 26, 1129-1144. https://doi.org/10. 1007/s11136-016-1454-8

47. Arias-de la Torre, J., Molina, A. J., Fernández-Villa, T., Artazcoz, L., \& Martín, V. (2018). Mental health, family roles and employment status inside and outside the household in Spain. Gaceta Sanitaria, 33(3), 235-241. https://doi.org/10.1016/j.gaceta.2017. 11.005

48. Tamayo-Fonseca, N., Nolasco, A., Moncho, J., Barona, C., Irles, M. Á., Más, R., ... Pereyrazamora, P. (2018). Contribution of the economic crisis to the risk increase of poor mental health in a region of spain. International Journal of Environmental Research and Public Health. http://doi.org/https://doi.org/10.3390/ijerp h15112517

49. McAneney, H., Tully, M. A., Hunter, R. F., Kouvonen, A., Veal, P., Stevenson, M., \& Kee, F. (2015). Individual factors and perceived community characteristics in relation to mental health and mental well-being. BMC Public Health, 15(1237), 1-13. https://doi.org/ 10.1186/s12889-015-2590-8

50. Steptoe, A., Deaton, A., \& Stone, A. A. (2015). Subjective wellbeing, health, and ageing. The Lancet. https://doi.org/10.1016/ S0140-6736(13)61489-0 
51. Norström, F., Virtanen, P., Hammarström, A., Gustafsson, P. E., \& Janlert, U. (2014). How does unemployment affect selfassessed health? A systematic review focusing on subgroup effects. BMC Public Health, 14(1), 1310. https://doi.org/10.1186/ 1471-2458-14-1310

52. Kidger, J., Brockman, R., Tilling, K., Campbell, R., Ford, T., Araya, R., ... Gunnell, D. (2016). Teachers' wellbeing and depressive symptoms, and associated risk factors: A large cross sectional study in English secondary schools. Journal of Affective Disorders, 192, 76-82. http://doi.org/https://doi.org/10.1016/j.jad.2015. 11.054

53. Lindbladh, E., \& Lyttkens, C. H. (2002). Habit versus choice: The process of decision-making in health-related behaviour. Social Science and Medicine, 55(3), 451-465. https://doi.org/10.1016/ S0277-9536(01)00180-0

54. Santini, Z. I., Fiori, K. L., Feeney, J., Tyrovolas, S., Haro, J. M., \& Koyanagi, A. (2016). Social relationships, loneliness, and mental health among older men and women in Ireland: A prospective community-based study. Journal of Affective Disorders, 204, 59-69. https://doi.org/10.1016/j.jad.2016.06.032

55. Kawachi, I., \& Berkman, L. F. (2001). Social ties and mental health. Journal of Urban Health: Bulletin of the New York Academy of Medicine, 78(3), 458-467.

56. Poscia, A., Stojanovic, J., La Milia, D. I., Duplaga, M., Grysztar, M., Moscato, U., ... Magnavita, N. (2018). Interventions targeting loneliness and social isolation among the older people: An update systematic review. Experimental Gerontology, 102, 133-144. http://doi.org/https://doi.org/10.1016/j.exger.2017.11.017

57. Whitehead, L., Jacob, E., Towell, A., Abu-qamar, M., \& ColeHeath, A. (2018). The role of the family in supporting the selfmanagement of chronic conditions: A qualitative systematic review. Journal of Clinical Nursing. https://doi.org/10.1111/jocn. 13775

58. Clarke, A., Friede, T., Putz, R., Ashdown, J., Martin, S., Blake, A., ... Stewart-Brown, S. (2011). Warwick-Edinburgh Mental Wellbeing Scale (WEMWBS): Validated for teenage school students in England and Scotland. A mixed methods assessment. BMC Public Health, 11(1), 487. http://doi.org/https://doi.org/10.1186/ 1471-2458-11-487

59. Böhnke, J. R., \& Croudace, T. J. (2016). Calibrating well-being, quality of life and common mental disorder items: Psychometric epidemiology in public mental health research. British Journal of Psychiatry, 209(2), 162-168. https://doi.org/10.1192/bjp.bp.115. 165530

60. Wilson, I. B., \& Cleary, P. (1995). Linking clinical variables with health-related quality of life. A conceptual model of patient outcomes. JAMA, 273(1), 59-65.

61. Dahlgren, G., \& Whitehead, M. (1991). Policies and strategies to promote social equity in health. Sweden: Stockholm.

62. Forero, C. G., Adroher, N. D., Stewart-Brown, S., Castellví, P., Codony, M., Vilagut, G., ... Alonso, J. (2014). Differential item and test functioning methodology indicated that item response bias was not a substantial cause of country differences in mental well-being. Journal of Clinical Epidemiolo, 67, 1364-1374. http:// doi.org/https://doi.org/10.1016/j.jclinepi.2014.06.017

63. Ferguson, K. D., McCann, M., Katikireddi, S. V., Thomson, H., Green, M. J., Smith, D. J., \& Lewsey, J. D. (2019). Evidence synthesis for constructing directed acyclic graphs (ESC-DAGs): A novel and systematic method for building directed acyclic graphs. International Journal of Epidemiology, dyz150, 1-8. https://doi. org/10.1093/ije/dyz150
64. Schmutte, P. S., \& Ryff, C. D. (1997). Personality and well-being: Reexamining methods and meanings. Journal of Personality and Social Psychology, 73(3), 549-559. https://doi.org/10.1037/00223514.73.3.549

65. Lederer, D. J., Bell, S. C., Branson, R. D., Chalmers, J. D., Marshall, R., Maslove, D. M., ... Vincent, J.-L. (2019). Control of confounding and reporting of results in causal inference studies. Guidance for authors from editors of respiratory, sleep, and critical care journals. Annals of the American Thoracic Society, 16(1), 22-28. http://doi.org/https://doi.org/10.1513/annalsats. 201808-564PS

66. CSHD. (2008). Closing the gap in a generation: Health equity through action on the social determinants of health. Final report of the Commission on Social Determinants of Health. Geneva: World Health Organization.

67. Vlassoff, C. (2007). Gender differences in determinants and consequences of health and illness. Journal of Health, Population, and Nutrition, 25(1), 47-61.

68. Parrish, R. G. (2010). Measuring population health outcomes. Preventing Chronic Disease, 7(4), A71.

69. Esch, P., Bocquet, V., Pull, C., Couffignal, S., Lehnert, T., Graas, M., ... Ansseau, M. (2014). The downward spiral of mental disorders and educational attainment: A systematic review on early school leaving. BMC Psychiatry. http://doi.org/https://doi.org/10. 1186/s12888-014-0237-4

70. Geyer, S., Hemström, Ö., Peter, R., \& Vågerö, D. (2006). Education, income, and occupational class cannot be used interchangeably in social epidemiology. Empirical evidence against a common practice. Journal of Epidemiology and Community Health, 60(9), 804-810. https://doi.org/10.1136/jech.2005.041319

71. Paul, K. I., \& Moser, K. (2009). Unemployment impairs mental health: Meta-analyses. Journal of Vocational Behavior, 74(3), 264-282. https://doi.org/10.1016/j.jvb.2009.01.001

72. Ribeiro, W. S., Bauer, A., Andrade, M. C. R., York-Smith, M., Pan, P. M., Pingani, L., ... Evans-Lacko, S. (2017). Income inequality and mental illness-related morbidity and resilience: A systematic review and meta-analysis. The Lancet Psychiatry, 4(7), 554-562. http://doi.org/https://doi.org/10.1016/S2215-0366(17) 30159-1

73. Wang, J., Mann, F., Lloyd-Evans, B., Ma, R., \& Johnson, S. (2018). Associations between loneliness and perceived social support and outcomes of mental health problems: A systematic review. BMC Psychiatry. https://doi.org/10.1186/ s12888-018-1736-5

74. Baglioni, C., Nanovska, S., Regen, W., Spiegelhalder, K., Feige, B., Nissen, C., ... Riemann, D. (2016). Sleep and mental disorders: A meta-analysis of polysomnographic research. Psychological Bulletin, 142(9), 969-990. http://doi.org/https://doi.org/ $10.1037 /$ bul0000053

75. Marc De Hert, Christoph U Correll, Julio Bobes, Marcelo Cetkovich-Bakmas, Dan Cohen, Itsuo Asai, ... Stefan Leucht. (2011). Physical illness in patients with severe mental disorders. I. Prevalence, impact of medications and disparities in health care. World Psychiatry, 10(1), 52-77. http://doi.org/https://doi.org/10.1002/j. 2051-5545.2011.tb00014.x

Publisher's Note Springer Nature remains neutral with regard to jurisdictional claims in published maps and institutional affiliations. 


\section{Authors and Affiliations}

\section{Natalia Soldevila-Domenech ${ }^{1,2,3} \mathbb{D} \cdot$ Carlos G. Forero $^{4}\left(\mathbb{D} \cdot\right.$ Itxaso Alayo $^{1,5} \cdot$ Jordina Capella $^{6,10}$ (D) Joan Colom ${ }^{6}$ (D) Davide Malmusi ${ }^{5,7}$ (D) Anna Mompart ${ }^{8} \cdot$ Philippe Mortier $^{1,5}$ (D) $\cdot$ Beatriz Puértolas $^{1,5} \cdot$ Néstor Sánchez $^{4}$ (D) Anna Schiaffino ${ }^{8,9}$ (D) Gemma Vilagut $^{1,5}$ (D) Jordi Alonso ${ }^{1,3,5}$ (D)}

$1 \quad$ Health Services Research Group, Epidemiology and Public Health Program, Hospital del Mar Medical Research Institute (IMIM), Carrer del Doctor Aiguader, 88, PRBB Building, 08003 Barcelona, Spain

2 Integrative Pharmacology and Systems Neurosciences Research Group, Neurosciences Research Program, Hospital del Mar Medical Research Institute (IMIM), Carrer del Doctor Aiguader, 88, PRBB Building, 08003 Barcelona, Spain

3 Department of Experimental and Health Sciences, Pompeu Fabra University (UPF), Carrer del Doctor Aiguader, 88, PRBB Building, 08003 Barcelona, Spain

4 School of Medicine, Universitat Internacional de Catalunya (UIC), Barcelona, Spain

5 CIBER en Epidemiología y Salud Pública (CIBERESP), Av. Monforte de Lemos, 3-5, 28029 Madrid, Spain
6 Programme on substance Abuse, Agency of Public Health of Catalonia, Carrer Roc Boronat, 81-95, 08005 Barcelona, Spain

7 Ajuntament de Barcelona, Barcelona, Spain

8 Direcció General de Planificació en Salut, Departament de Salut, Generalitat de Catalunya, Travessera de les Corts, 131-159, 08028 Barcelona, Spain

9 Institut Català D'Oncologia, Gran Via de l'Hospitalet 199-203, 08908 l'Hospitalet de Llobregat, Spain

10 Direcció General d'Ordenació i Regulació Sanitàries, Departament de Salut, Generalitat de Catalunya, Travessera de les Corts, 131-159, 08028 Barcelona, Spain 